\title{
Bandwidth Enhancement of UWB Microstrip Antenna with a Modified Ground Plane
}

\author{
N. Prombutr, ${ }^{1}$ P. Kirawanich, ${ }^{1}$ and P. Akkaraekthalin ${ }^{2}$ \\ ${ }^{1}$ Electrical Engineering Department, Mahidol University, Nakorn Pathom 73170, Thailand \\ ${ }^{2}$ Electrical Engineering Department, King Mongkut's Institute of Technology North Bangkok, Bangkok 10800, Thailand
}

Correspondence should be addressed to N. Prombutr, egnpb@mahidol.ac.th

Received 19 January 2009; Accepted 22 July 2009

Recommended by Afshin Daryoush

This article presents a bandwidth enhancing technique using a modified ground plane with diagonal edges, rectangular slot, and T-shape cut for the design of compact antennas. The proposed low-cost, compact-size circular patch antenna on $3 \mathrm{~cm} \times 5.1 \mathrm{~cm}$ printed circuit board (FR-4) is designed and validated through simulations and experiments. Results show that the T-shaped ground plane with the presence of the diagonal cuts at the top corners and the rectangular slots can increase the bandwidth. Return losses of -19 and $-26 \mathrm{~dB}$ for the first and second resonant frequencies, respectively, can be achieved when the depth of the diagonal cut is $5 \mathrm{~mm}$, the dimension of each rectangular slot is $5 \times 3 \mathrm{~mm}$, and the T-shaped size is $8 \times 4 \mathrm{~mm}$, providing a $28.67 \%$ wider bandwidth than FCC standard.

Copyright (C) 2009 N. Prombutr et al. This is an open access article distributed under the Creative Commons Attribution License, which permits unrestricted use, distribution, and reproduction in any medium, provided the original work is properly cited.

\section{Introduction}

Ultra-wideband (UWB) technology has been regarded as one of the most promising wireless technologies that have a capability of revolutionizing high data rate transmission. Since the FCC release of UWB wireless communication bandwidth of $7.5 \mathrm{GHz}(3.1-10.6 \mathrm{GHz})$, a number of new developed techniques to support high data rate wireless communication for the next generation technologies have been rapidly increasing. Basically, the maximum achievable data rate or capacity for the ideal band-limited additive white Gaussian noise (AWGN) channel is related to the bandwidth and the signal-to-noise ratio through ShannonNyquist criterion $[1,2]$ :

$$
C=B \log _{2}(1+\mathrm{SNR}),
$$

where $C$ denotes the maximum transmit data rate, $B$ stands for the channel bandwidth, and SNR is the signal-to-noise ratio. From this principle, the transmit data rate can be enhanced by increasing either the bandwidth occupation or the transmission power. However, the transmission power cannot be readily increased since many portable devices are battery powered and the potential interference should also be avoided. Thus, a large frequency bandwidth seems to be the proper solution to achieve a high data rate.

In this article, we report a technique to enhance the bandwidth using a microstrip-fed planar circular disc monopole [3]. The circular disc monopole with a $50-\Omega$ microstrip feed line is fabricated on the FR4 substrate. To improve the bandwidth, we modified the original ground plane to be T-shaped with diagonal cuts at the top corners and rectangular slots on the body. Applications of corner cut technique have been previously employed to improve the impedance bandwidth for microstrip patch antennas [46]. The preliminary simulation results of our proposed antenna are compared with the measured ones. Following this introduction, the rest of the paper is organized as follows. The detail of the antenna design and preliminary results from simulations are described in Section 2, and Section 3 discusses the experimental results. This work concludes in Section 4 .

\section{Antenna Design}

The geometries of the antennas in our study are shown in Figure 1. We use the microstrip structure because it offers many advantages, such as being compact, inexpensive, and 


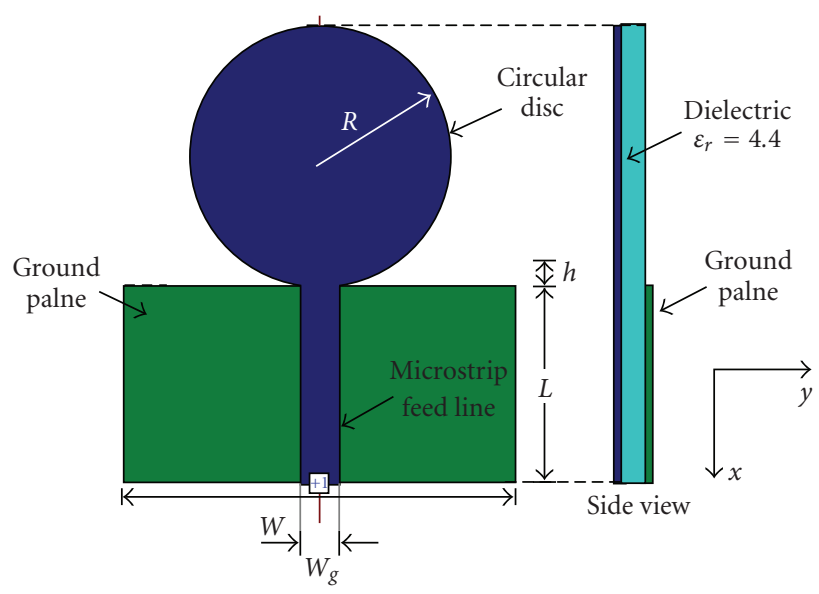

(a)

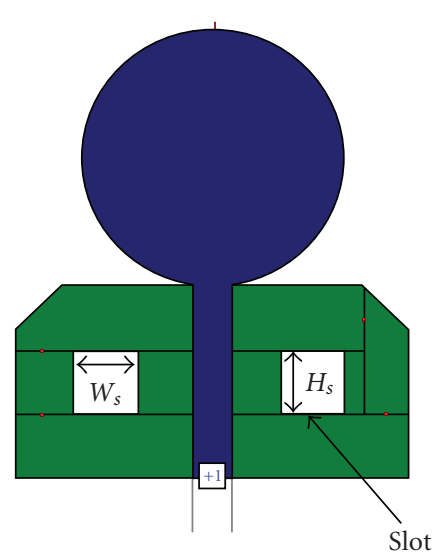

(c)

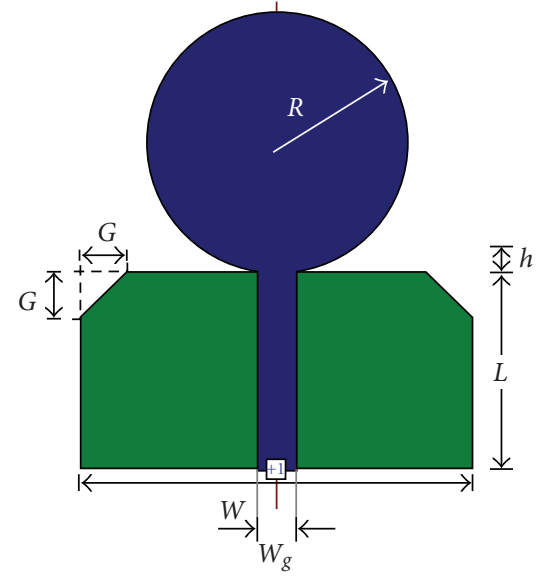

(b)

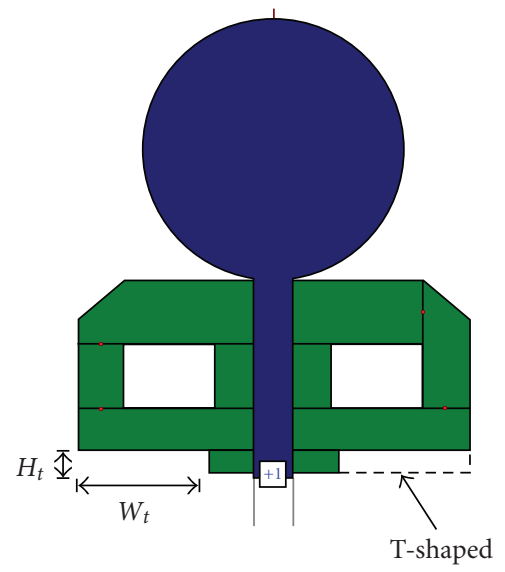

(d)

FIGURE 1: Geometries of the circular microstrip antennas (a) original shape, (b) with diagonal edges, (c) with slots, and (d) with T-shaped cut on the ground plane.

light weight. On the other hand, a lower bandwidth is a shortcoming for this structure. Our objectives are to modify the structure and incorporate the techniques to improve the bandwidth. In what follows, brief analysis of the parametric studies to achieve the optimum values of return loss and bandwidth is discussed.

The antenna configuration in Figure 1(a) is first used for the parametric study. The planar circular disc monopole is fabricated on a $3 \mathrm{~cm} \times 5.1 \mathrm{~cm} \times 0.16 \mathrm{~cm}$ FR-4 board $\left(\varepsilon_{r}=\right.$ 4.4 , thickness $=1.6 \mathrm{~mm}$ ) with a feed line and a finite ground plane. The radius $R$ of the circular monopole disc is the first parameter to optimize for the lowest return loss and widest bandwidth while the other parameters are kept constant. The width $w_{g}$ of the microstrip feed line is designed to be $3 \mathrm{~mm}$ for the impedance of $50 \Omega$. The results in Figure 2(a) show that the increase of the radius $R$ will result in reductions of the return loss and the bandwidth. Even though the disc radius of $11 \mathrm{~mm}$ provides the lowest return loss, we chose the radius of $10 \mathrm{~mm}$ for the better bandwidth.

The next tuning parameter is the gap between the top section of the ground plane and the bottom portion of the disc. The parameter $h$ is positive when the bottom of the disc is at the higher level than the top of the ground plane. The same can be said for the negative value of $h$ in the opposite direction. The results of the return loss and bandwidth as a function of the parameter $h$ are shown in Figure 2(b). Compared with the negative value of $h$, the positive value gives the higher return loss at high frequency while providing the lower return loss at low frequency. We chose the parameter $h$ to be zero (the bottom of the disc is at the same level as the top of the ground plane) for a compromise between the observed return loss at high and low frequencies.

To accomplish a compact size design, the minimum size of the ground plane is desirable. The parameter to study is the length $L$ of the ground plane. From the results in Figure 3(a), the length of the ground plane will have only slight effect on the bandwidth. We selected the length of $15 \mathrm{~mm}$ for a wider bandwidth and moderately small size. Next, we studied the parameter $W$ (the width of the ground plane), and the results as a function of $W$ are shown in Figure 3(b). The increase in the width gives the lower return loss at low frequency. 


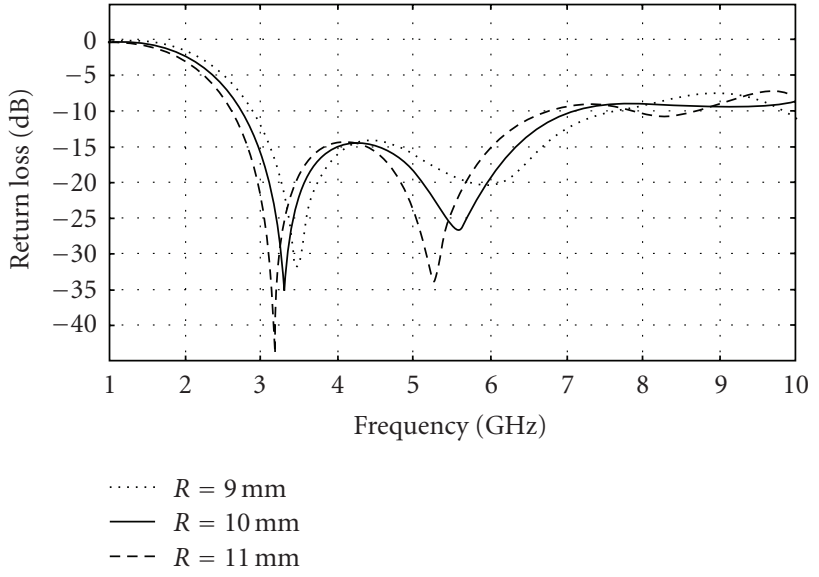

(a)

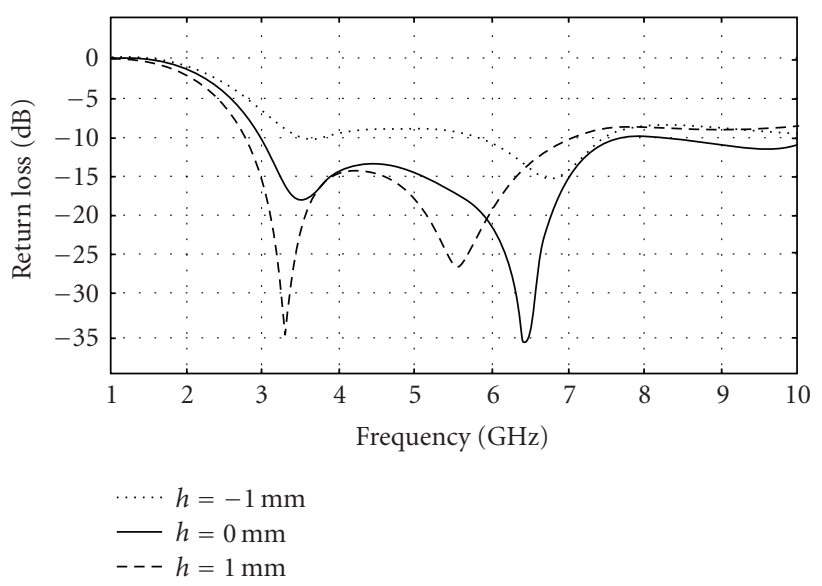

(b)

Figure 2: Return losses as functions of (a) disc radius $R$ and (b) vertical gap.

Additionally, the second resonant frequency is shifting to the lower frequency region while increasing the width. We preferred the width of $30 \mathrm{~mm}$ due to the appropriately low return loss and the occurrence of the second resonance at around $6.4 \mathrm{GHz}$. From the above parameter selection, the result for the return loss is shown in Figure 4 where the antenna is applicable from $2.957 \mathrm{GHz}$ to $11.892 \mathrm{GHz}$, providing a bandwidth of $8.935 \mathrm{GHz}$.

To further improve the bandwidth of the antenna, we removed the top corners of the ground plane, resulting in symmetrical diagonal edges. The resultant antenna is shown in Figure 1(b) with the parameter $G$ associated with the cut area. The return losses in Figure 5 show that the parameter $G$ only has a slight effect at low frequency while it has a significant effect at high frequency. The parameter $G$ of $5 \mathrm{~mm}$ seems to offer a relatively low return loss and an appropriately wide bandwidth. This antenna can be used from $2.957 \mathrm{GHz}$ to 12.1 GHz, providing a bandwidth of $9.15 \mathrm{GHz}$. Compared with the result in Figure 4, associated with the original shape, the antenna with diagonal edges on the ground plane can increase the bandwidth for approximately $0.21 \mathrm{GHz}$ as shown in Figure 6.

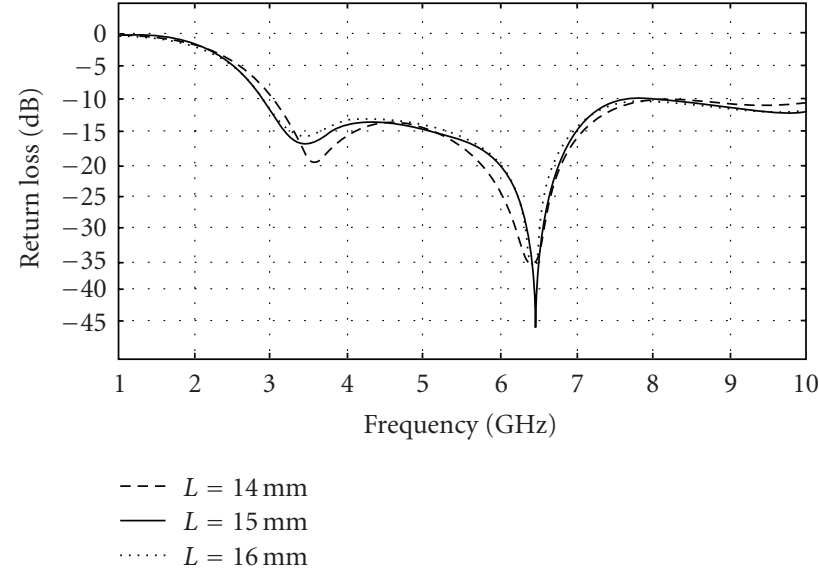

(a)

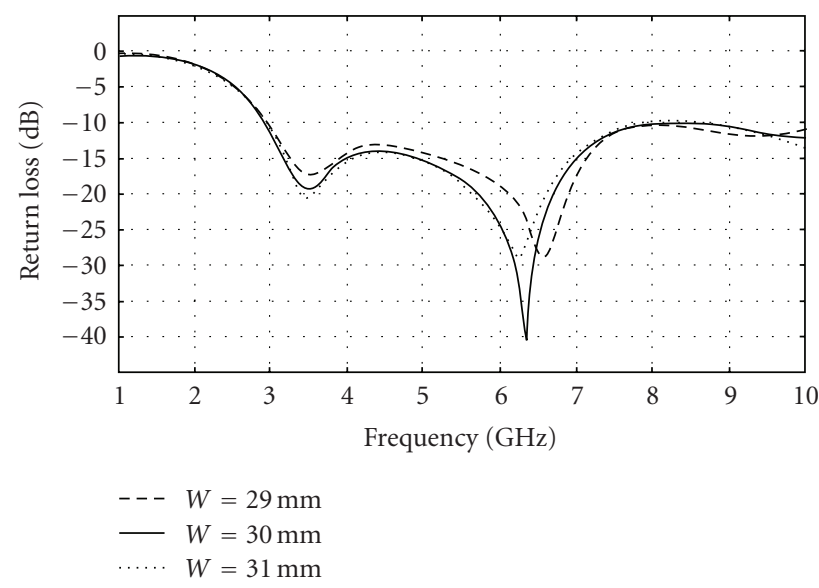

(b)

Figure 3: Return losses as functions of (a) the length and (b) the width of the ground plane.

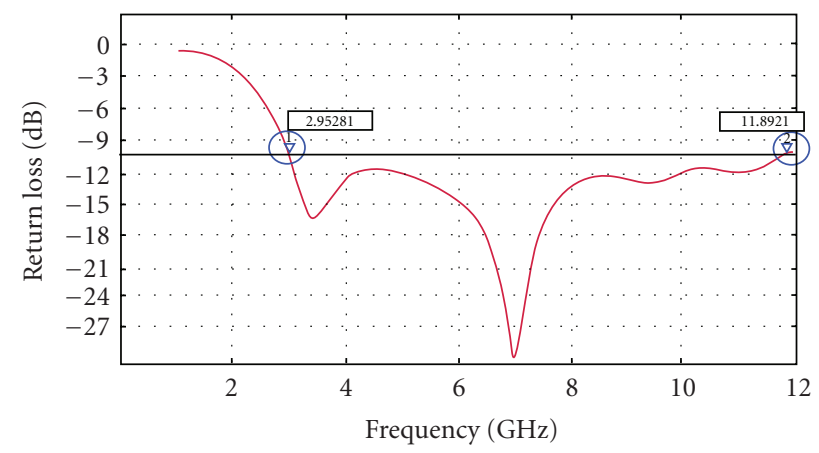

Figure 4: Return loss with parameters $R=10 \mathrm{~mm}, h=0 \mathrm{~mm}, L=$ $15 \mathrm{~mm}$, and $W=30 \mathrm{~mm}$. The resultant bandwidth is approximately $8.9 \mathrm{GHz}$.

To improve the impedance matching in the UWB frequencies, the rectangular slot technique [7-9] is employed. This method introduces two identical slots at the center of the ground plane, shown in Figure 1(c), in order to mitigate the reflection of the surface current, thus adjusting the antenna impedance and reducing the return loss. The 


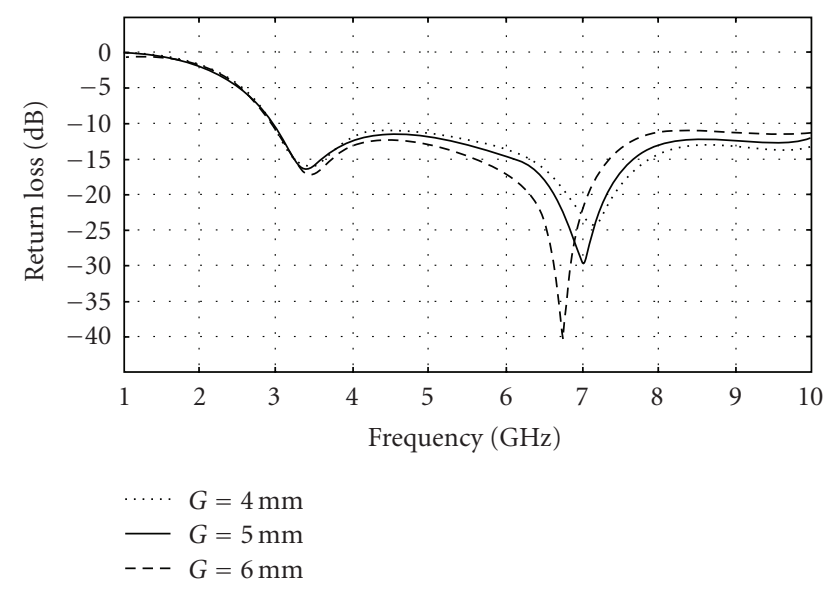

FIGURE 5: Return losses as a function of the parameter $G$ associated with the removed area on the ground plane.

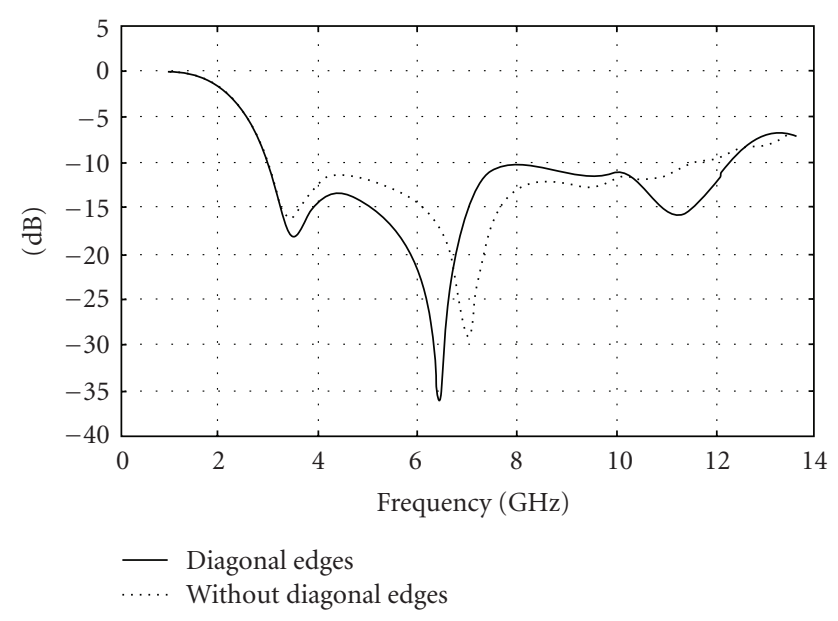

Figure 6: Comparison of return loss $(\Gamma)$ between the original antenna and the antenna with diagonal edges on the ground plane.

optimum values of the slot width $\left(W_{s}\right)$ and slot height $\left(H_{s}\right)$ are 5 and $3 \mathrm{~mm}$, respectively. The return losses of antenna with slot dimensions are shown in the Figure 7.

In addition to diagonal edges and rectangular slots, the ground plane was reshaped as a letter "T" (see Figure 1(d)). The T-shaped ground plane [10] achieves the highest bandwidth when the width $\left(W_{t}\right)$ and the height $\left(H_{t}\right)$ of the cut positions are $8 \mathrm{~mm}$ and $4 \mathrm{~mm}$, respectively, where the results can be seen in Figure 8. A comparison among the antennas with modified ground plane (see Figures 1(b), 1(c) and 1(d)) is shown in Figure 9. The results show that an accumulation of ground plane modifications introduces an extra return loss dip, resulting in the optimal bandwidth.

\section{Experimental Result and Discussion}

The photograph of the fabricated proposed circular disc antennas with diagonal edges and slots on the T-shaped ground plane is shown in Figure 10. The comparison

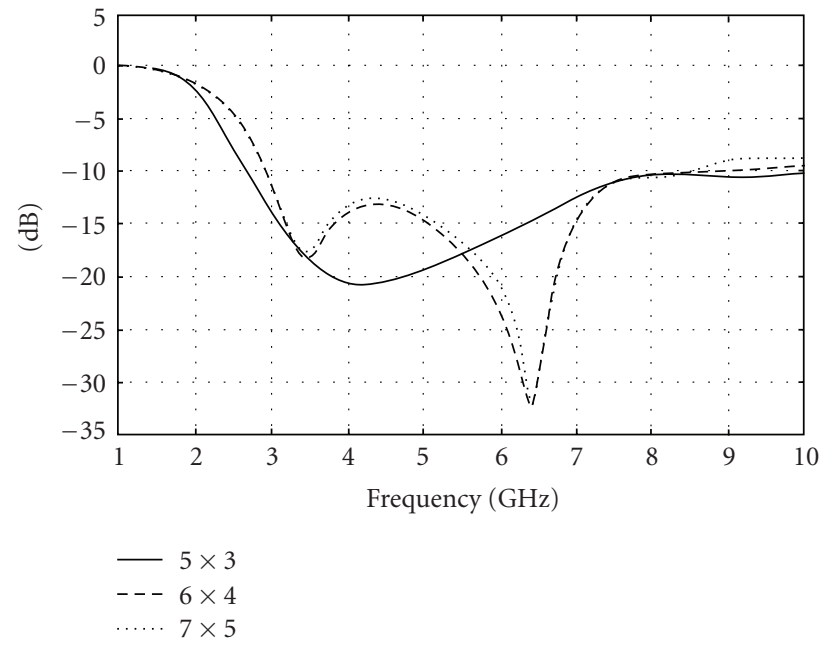

Figure 7: Return loss $(\Gamma)$ of antenna with slot dimension.

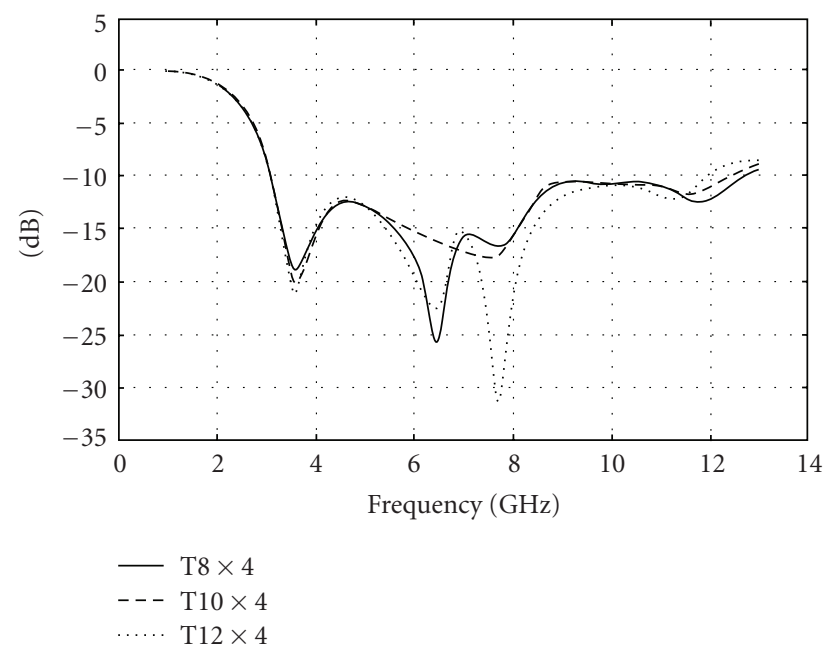

FIGURE 8: Return losses of antenna as a function of T-shaped cut dimension.

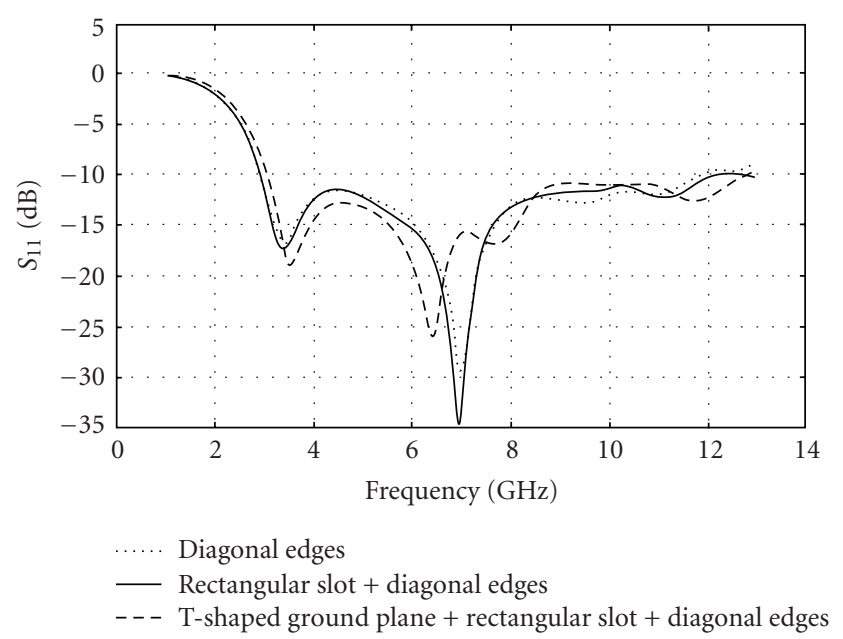

Figure 9: Comparison of return lossless of all three antennas in Figures 1(b), 1(c), and 1(d). 


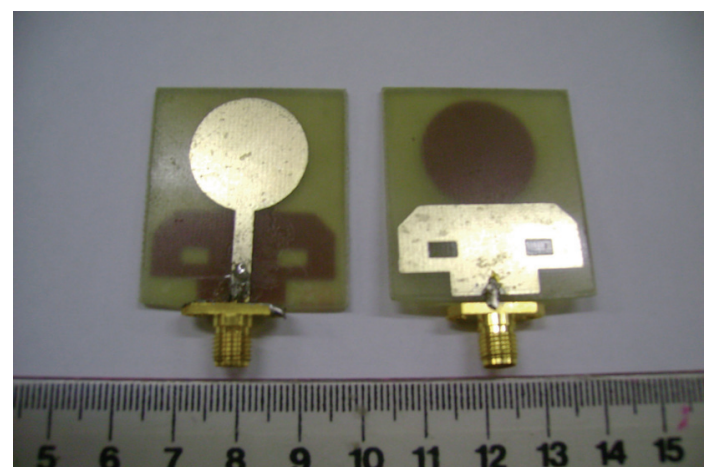

FIGURE 10: Photograph of the fabricated proposed antenna.

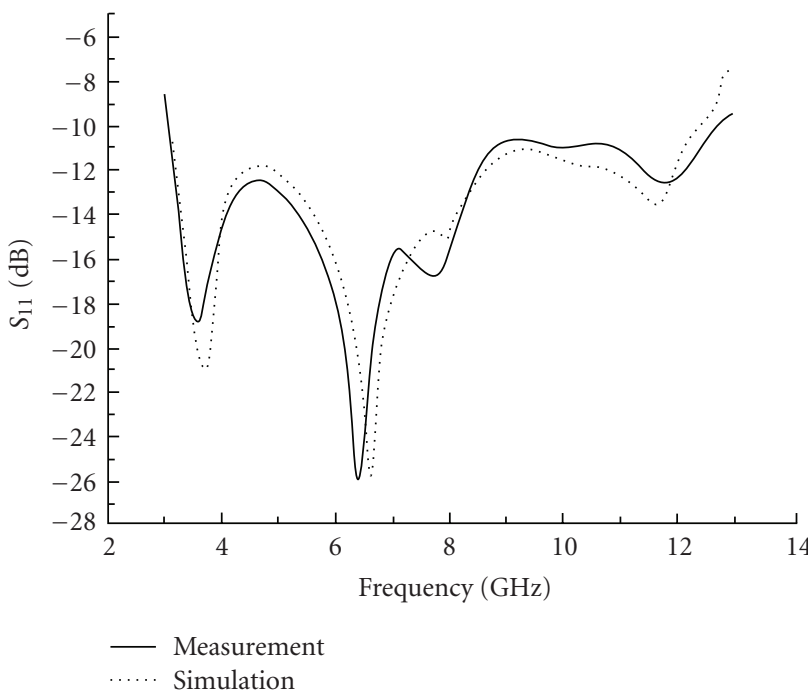

FIGURE 11: Comparison between simulated and measured results of the proposed circular microstrip antenna.

between the simulated results using commercial highfrequency structure simulator (IE3D) and the results from the measurement of the fabricated antenna using an Agilent PNA-L series N5230A vector network analyzer is shown in Figure 11. The measured result is relatively close to that obtained from simulation. The discrepancy of the return loss at the first resonant frequency would be caused by the size difference of the circular discs [11-15] between the simulation model and the fabrication as mentioned in the previous section.

The measured radiation patterns of the antenna on the E-plane and $\mathrm{H}$-plane at resonant frequencies of $3.2 \mathrm{GHz}$, $6.40 \mathrm{GHz}$, and $7.65 \mathrm{GHz}$ are shown in Figures 12, 13 and 14, respectively. The results show that reasonable omnidirectional radiation pattern can be observed along the $\mathrm{H}$ plane. The radiation pattern similar to that of the short dipole can be observed on the E-plane. Consistency of the patterns can also be observed across the operating frequencies. The E-plane copolarization patterns are bidirectional and $\mathrm{H}$-plane copolarization patterns are omnidirectional or nearly omni-directional at higher frequency, like a regular dipole [16]. When the frequency increases to $7.65 \mathrm{GHz}$,

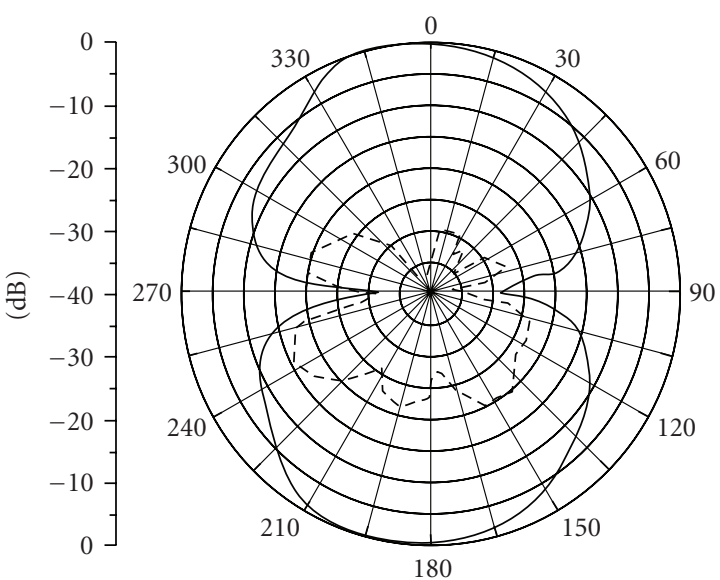

(a)

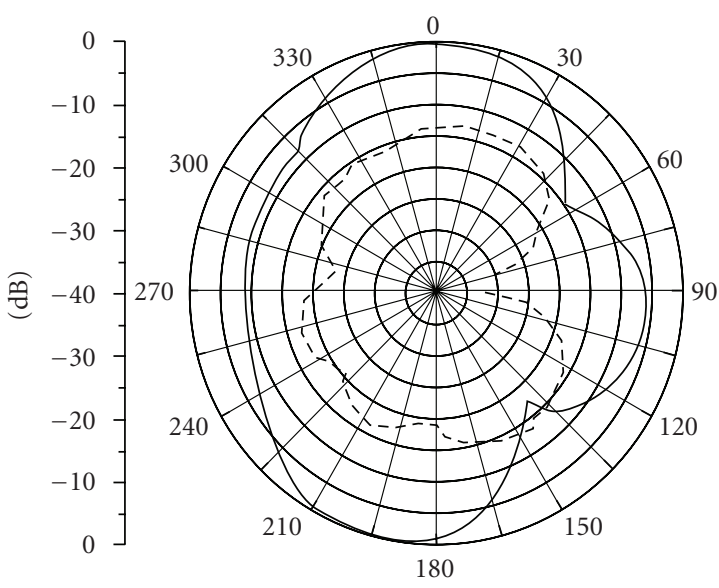

(b)

Figure 12: Measured co-(solid line) and cross-(dash line) polarization radiation patterns at $3.52 \mathrm{GHz}$. (a) E-plane patterns, and (b) H-plane patterns.

the direction of the electric field becomes complex. As a result, the cross-polarization level rises and ripples appear in the E-plane but the $\mathrm{H}$-plane is still omni-directional. As a conclusion, the radiation pattern of the proposed antenna is almost stable in the operation band $(3-12.615 \mathrm{GHz})$. Figure 15 shows the relatively almost constant gain of optimized antenna from 1 to $13 \mathrm{GHz}$ with some changes about $8 \mathrm{GHz}$ and $10 \mathrm{GHz}$ and this gain is not nearly change but it seem to be reduced at the higher frequency.

Several important observations from the results of the return loss are detailed as follows. First, the diameter of the circular disc basically corresponds to the quarter wavelength of the associated resonant frequency $[17,18]$. A variation of resonant frequencies as a function of the disc radius in Figure 2(a) shows that the circular disc is capable of supporting multiple resonant modes through $2 R=n \lambda / 4$, where $n$ is the mode number and $\lambda$ is the wavelength. In addition, the parameter $h$ results in not only the resonant frequency shifting but also the return loss level between the first and second resonant frequencies. For the second observation, the first resonance is barely changed for all different 


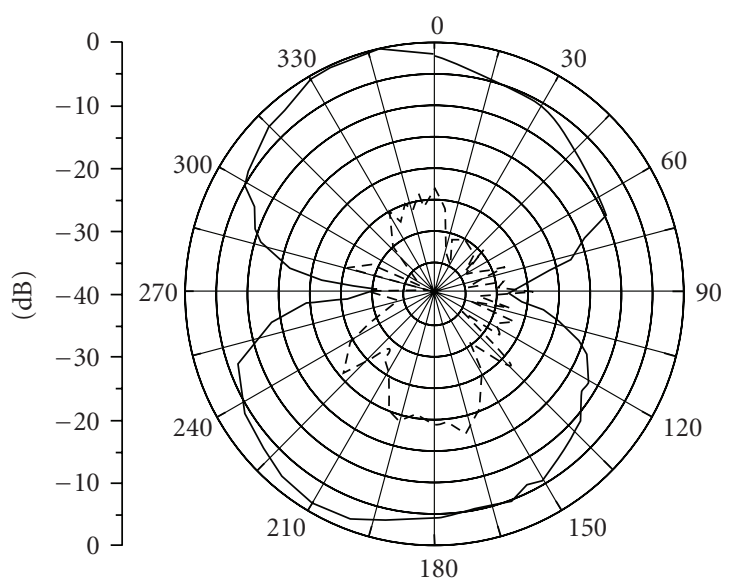

(a)

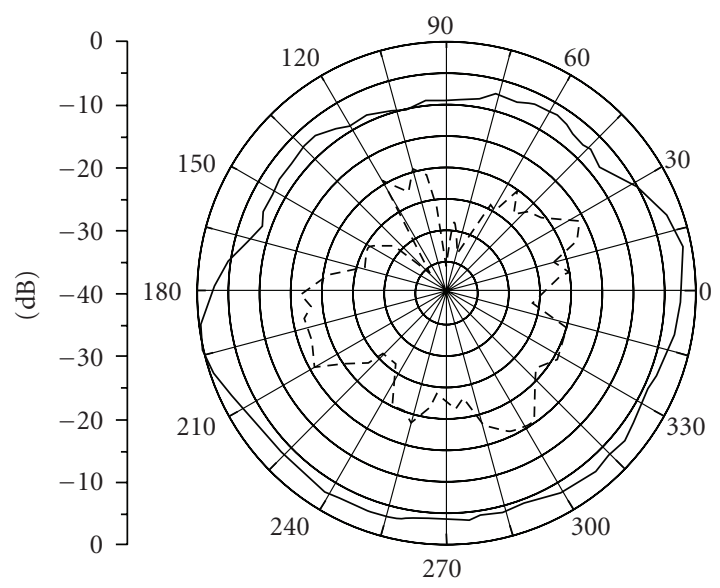

(b)

Figure 13: Measured co-(solid line) and cross-(dash line) polarization radiation patterns at $6.40 \mathrm{GHz}$. (a) E-plane patterns, and (b) H-plane patterns.

ground plane sizes as shown in Figures 3(a) and 3(b). When the ground plane is reduced in either length or width, the first resonant frequency is shifted slightly at around $3 \mathrm{GHz}$. These two observations imply that the resonant frequency is typically determined by the circular disc size and slightly detuned by the size of the ground plane. The observation is that, as shown in Figure 2, the first resonant frequency is dependent on the size of the circular disc as mentioned above while the second resonant frequency and the bandwidth obey the dimension of the cut area at the ground plane corners $[19,20]$. The rectangular slot and T-shape cut are used to improve the impedance matching of the propose antenna to reduce the reflection of surface current, thus adjusting the parameters of slot and T-shape cut to reduce return loss or enhance the bandwidth of UWB antenna.

\section{Conclusion}

A compact antenna and a technique to increase its bandwidth have been proposed and implemented. The proposed low-cost and compact-size circular patch antenna

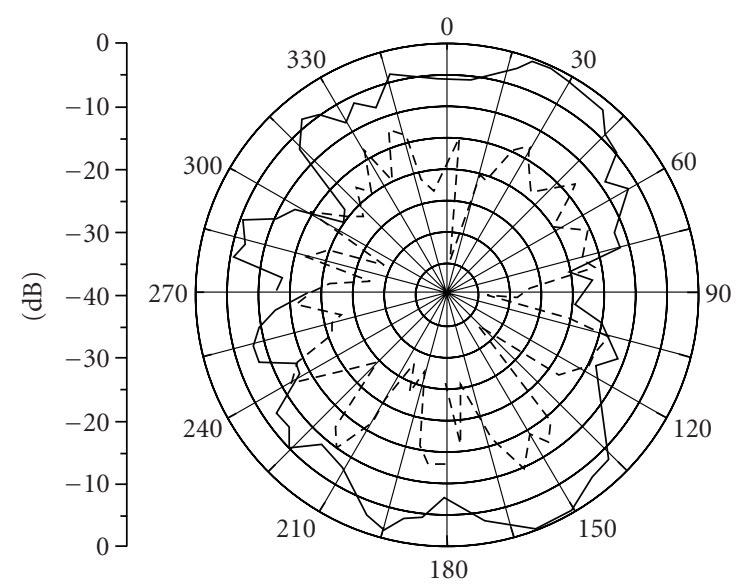

(a)

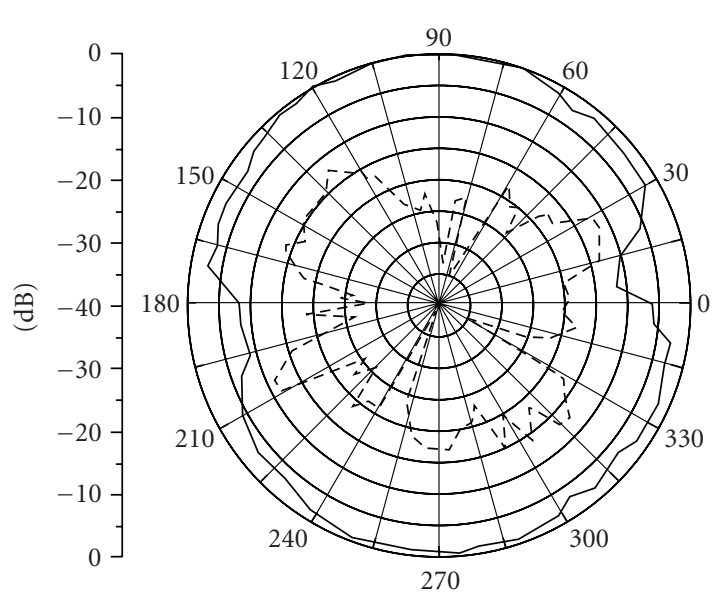

(b)

FIGURe 14: Measured co-(solid line) and cross-(dash line) polarization radiation patterns at $7.65 \mathrm{GHz}$. (a) E-plane patterns, and (b) H-plane patterns.

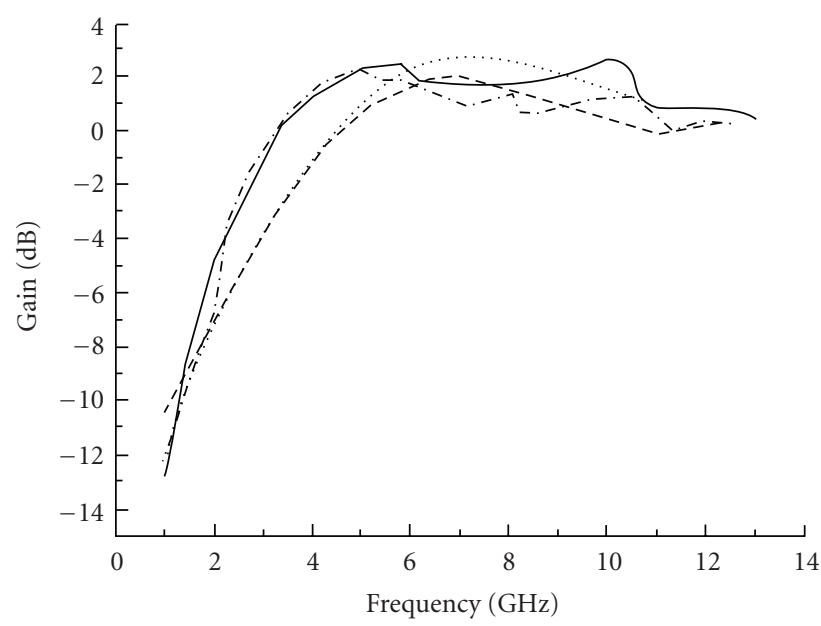

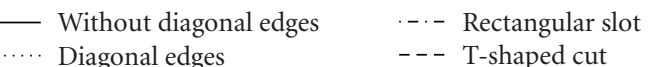

FIGURE 15: Gain of the optimized antenna. 
on $3 \mathrm{~cm} \times 5.1 \mathrm{~cm}$ printed circuit board (FR-4) is designed and validated through simulations and experimental observations. Results show that the bandwidth can be tunable depending mainly on the circular disc size and the vertical gap between the disc and the ground plane. With the presence of the diagonal cut areas at the corners of the ground plane, the bandwidth can be further improved. Return losses of -17 and $-30 \mathrm{dBs}$ for the first and second resonant frequencies, respectively, can be achieved when the depth of the diagonal cut is at optimum value of $5 \mathrm{~mm}$, rectangular slot $(5 \times 3 \mathrm{~mm})$, and T-shape cut $(8 \times 4 \mathrm{~mm})$ providing a maximum $28.67 \%$ wider bandwidth $(3-12.615 \mathrm{GHz})$ than the FCC recommended standard of $3.1-10.6 \mathrm{GHz}$. Finally, the size of the ground plane, which has an insignificant impact on the performance, can be further reduced to around $30 \mathrm{~cm} \times 1.5 \mathrm{~cm}$ to meet a compact size design.

\section{References}

[1] J. G. Proakis, Digital Communications, McGraw-Hill, New York, NY, USA, 1989.

[2] C. E. Shannon, "A mathematical theory of communication," The Bell System Technical Journal, vol. 27, pp. 379-423, 623656, 1948.

[3] J. Liang, C. C. Chiau, X. Chen, and C. G. Parini, "Study of a printed circular disc monopole antenna for UWB systems," IEEE Transactions on Antennas and Propagation, vol. 53, no. 11, pp. 3500-3504, 2005.

[4] A. K. Sharma and A. Mittal, "Diagonal slotted diamond shaped dual circularly polarized microstrip patch antenna with dumbbell aperture coupling," in Proceedings of the 8th European Conference on Wireless Technology, pp. 463-465, 2005.

[5] N. Prombutr, J. Pakeesirikul, T. Theatmongkol, and S. Suangool, "Dual-band coplanar waveguide antenna design by using U-slot with diagonal edge," in Proceedings of the 21st International Technical Conference on Circuits/Systems, Computers and Communications, vol. 3, pp. 117-120, Chaingmai, Thailand, 2006.

[6] M. A. Alkanhal and A. F. Sheta, "A novel dual-band reconfigurable square-ring microstrip antenna," Progress in Electromagnetics Research, vol. 70, pp. 337-349, 2007.

[7] F. G. Kharakhili, M. Fardis, G. Dadashzadeh, A. Ahmadi, and N. Hojjat, "Circular slot with a novel circular microstrip open ended microstrip feed for UWB applications," Progress in Electromagnetics Research, vol. 68, pp. 161-167, 2007.

[8] Y. Song, Y.-C. Jiao, G. Zhao, and F.-S. Zhang, "Multiband CPW-FED triangle-shaped monopole antenna for wireless applications," Progress in Electromagnetics Research, vol. 70, pp. 329-336, 2007.

[9] S. Sadat, M. Houshmand, and M. Roshandel, "Design of a microstrip square-ring slot antenna filled by an H-shape slot for UWB applications," Progress in Electromagnetics Research, vol. 70, pp. 191-198, 2007.

[10] J.-J. Jiao, G. Zhao, F.-S. Zhang, H.-W. Yuan, and Y.-C. Jiao, "A broadband CPW-FED T-shape slot antenna," Progress in Electromagnetics Research, vol. 76, pp. 237-242, 2007.

[11] R. Zaker, Ch. Ghobadi, and J. Nourinia, "A modified microstrip-fed two-step tapered monopole antenna for UWB and WLAN applications," Progress in Electromagnetics Research, vol. 77, pp. 137-148, 2007.

[12] S. L. S. Yang, K. F. Lee, A. A. Kishk, and K. M. Luk, "Design and study of wideband single feed circularly polarized microstrip antennas," Progress in Electromagnetics Research, vol. 80, pp. 45-61, 2008.

[13] Y. Yang, Y. Wang, and A. E. Fathy, "Design of compact vivaldi antenna arrays for UWB see through wall applications," Progress in Electromagnetics Research, vol. 82, pp. 401-418, 2008.

[14] R. Fallahi, A.-A. Kalteh, and M. G. Roozbahani, "A novel UWB elliptical slot antenna with band-notched characteristics," Progress in Electromagnetics Research, vol. 82, pp. 127-136, 2008.

[15] M. Abbaspour and H. R. Hassani, "Wideband star-shaped microstrip patch antenna," Progress in Electromagnetics Research Letters, vol. 1, pp. 61-68, 2008.

[16] X.-C. Yin, C.-L. Ruan, C.-Y. Ding, and J.-H. Chu, "A planar u type monopole antenna for uwb applications," Progress in Electromagnetics Research Letters, vol. 2, pp. 1-10, 2008.

[17] Q. Liu, C.-L. Ruan, L. Peng, and W.-X. Wu, "A novel compact archimedean spiral antenna with gap-loading," Progress in Electromagnetics Research Letters, vol. 3, pp. 169-177, 2008.

[18] A. Danideh, R. Sadeghi-Fakhr, and H. R. Hassani, "Wideband co-planar microstrip patch antenna," Progress in Electromagnetics Research Letters, vol. 4, pp. 81-89, 2008.

[19] M. Albooyeh, N. Komjani, and M. Shobeyri, "A novel crossslot geometry to improve impedance bandwidth of microstrip antennas," Progress in Electromagnetics Research Letters, vol. 4, pp. 63-72, 2008.

[20] G.-P. Gao, X.-X. Yang, J.-S. Zhang, and J.-X. Xiao, "A printed volcano smoke antenna for UWB and WLAN communications," Progress in Electromagnetics Research Letters, vol. 4, pp. 55-61, 2008. 

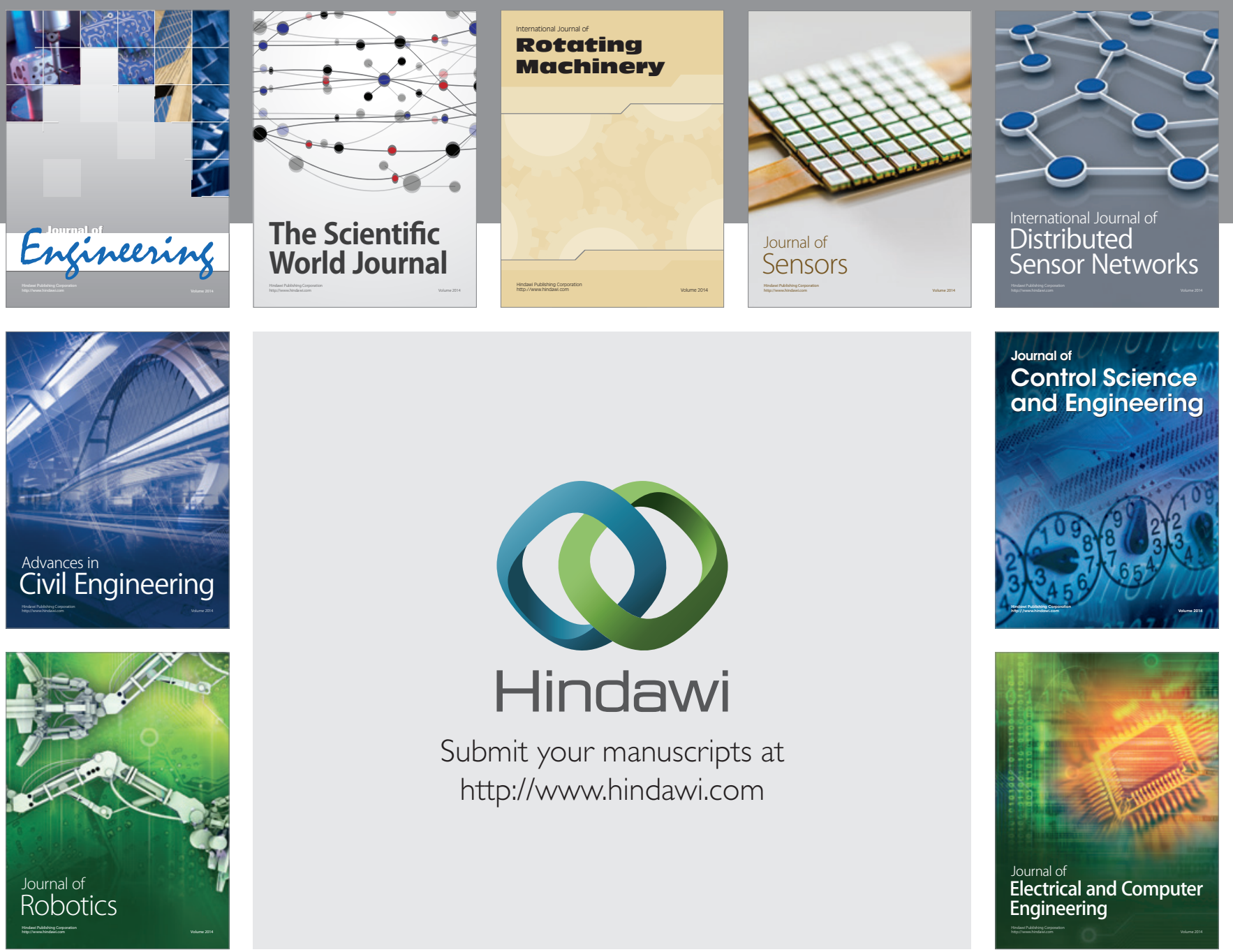

Submit your manuscripts at

http://www.hindawi.com
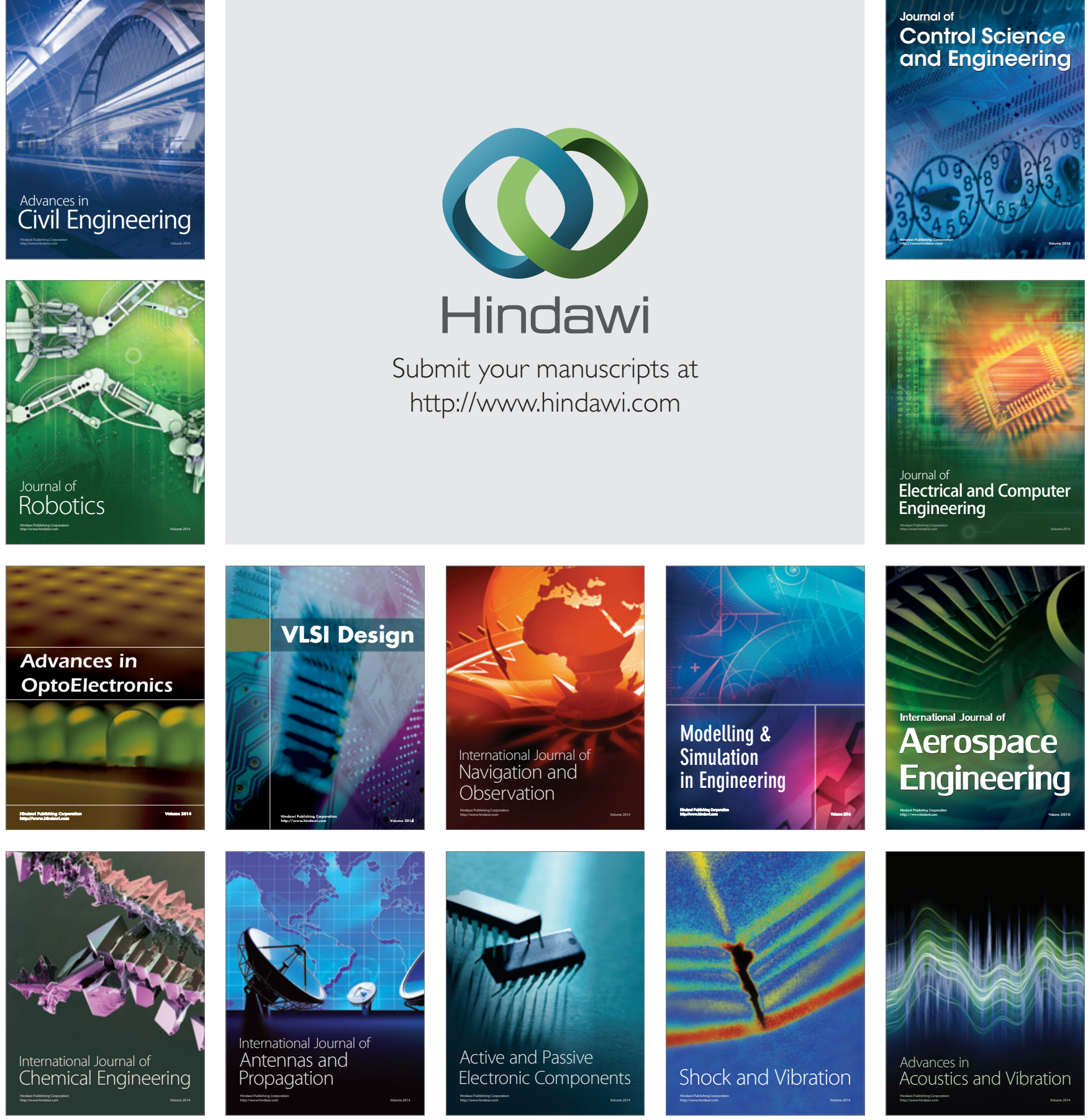